\title{
La transformación de las políticas públicas de juego de azar en España'
}

\author{
José Ignacio Cases \\ Universidad Carlos III de Madrid \\ jcases@polsoc.uczm.es
}

\begin{abstract}
Resumen
Tras 35 años de juego autorizado en España, en mayo de 2011 ha entrado en vigor la Ley de Regulación de Juego. En un estudio explicativo de las transformaciones que han abocado a la aparición de este nuevo marco legislativo, el autor, tras examinar la trayectoria histórica de la regulación del juego de azar y analizar la complejidad del escenario actual, sostiene la tesis de que las políticas públicas en la materia han sido temerosas e insuficientes porque, pretendiendo defender valores morales, en realidad aspiraban a preservar los intereses recaudatorios. Además, las administraciones públicas no han sabido prever el impacto de internet. Se analizan en este texto las consecuencias de ello: la entrada en España de operadores no controlados, la aparición de nuevos y fortísimos intereses colaterales y la competencia desleal con las empresas operadoras autorizadas para el juego presencial. Esto ha llevado, en definitiva, a que la Hacienda Pública dejara de recaudar los impuestos y tasas que esta nueva actividad debería haber devengado.
\end{abstract}

Palabras clave Juegos de azar, Historia del juego, impuestos sobre el juego, competencia desleal, internet, autoridad reguladora.

\section{Gaming of Chance Policy Changes in Spain}

\begin{abstract}
After 35 years of authorised gaming in Spain, May 2011 saw the enactment of Spain's Gambling Regulation Act. In an explanatory study of the transformations focusing on the emergence of this new legislative framework, after examining the historical background of the regulation of gambling and analysing the complexity of the current scenario, the author takes the view that public policy on gambling over the years has been fearful and inadequate because while pretending to defend moral values, in reality these policies aspired to preserve the interests of revenue collection. In addition, governments have failed to foresee the impact of the Internet. The articles examines the consequences of this failure: the entry into Spain of unregulated operators, the emergence of new and strong collateral interests and unfair competition with licensed operating companies of physical gaming establishments. This has ultimately prevented the Treasury from collecting the taxes and charges that this new activity should have accrued.
\end{abstract}

Keywords

Gaming chance, History of Gaming, gaming taxes, unfair competition, internet, regulatory authority.

1 El autor quiere expresar su agradecimiento al Prof. Javier Redondo por la ayuda prestada. 


\section{INTRODUCCIÓN}

La tramitación por la vía de urgencia del proyecto de Ley de Regulación del Juego, refleja muy significativamente cuáles han sido las circunstancias en las que los sucesivos gobiernos (UCD, PSOE, PP y PSOE de nuevo) han desarrollado sus políticas públicas respecto de una actividad económica y social de notable envergadura. Porque hay que tener en cuenta que este proyecto es el primer texto con este mismo rango que la democracia promulga después de más de treinta años desde que la práctica del juego de azar quedara parcialmente autorizada. Del mismo modo, y más adelante nos detendremos en ello, hay que tener presente, como ha señalado Subirats (1996: 158-159), que "no puede aceptarse la idea de que la gestión en las Administraciones Públicas pueda hacer caso omiso del entorno político en el que se mueve, o solo entenderlo como incrustación irracional o limitación estructural que solo afecta a las fases no estrictamente técnicas del proceso gerencial”.

Este artículo pretende exponer las circunstancias y las consecuencias de esa "incrustación irracional", además de adentrarse en las causas de una parálisis, al menos parcial; o tal vez de un quehacer erróneo. Asimismo pretende identificar y ubicar a los actores que han participado en la regulación y enumerar las sucesivas etapas por las que ha transcurrido la acción gubernamental, tanto estatal como autonómica. Es decir, queremos analizar y desarrollar la agenda institucional; o, en otras palabras (Tamayo Sáez, 1997: 290-291), determinar cuál es el poder y la capacidad de presión de los grupos de interés; cuáles son los sesgos culturales, el peso de la tradición y las actitudes y valores de los decisores públicos en el ámbito que nos ocupa.

La urgencia en la tramitación del Proyecto de Ley de Regulación del Juego viene señalada en la amplia exposición de motivos del mismo². En ella, el legislador reconoce directa y claramente que la actividad del juego de azar ${ }^{3}$ ha desbordado de modo

2 Desde la despenalización del juego en el Real Decreto-Ley 16/1977, de 25 de febrero, por el que se regulan los aspectos penales, administrativos y fiscales de los juegos de suerte, envite o azar y apuestas, y debido fundamentalmente a la irrupción de los nuevos servicios de comunicaciones electrónicas y a la utilización de los servicios de juego interactivos a través de internet, ha cambiado de forma sustancial, tanto en España como en otros países de su entorno, la concepción tradicional del juego. Durante muchos años, el régimen jurídico del juego ha sufrido pocos cambios. Sin embargo, recientemente, como consecuencia de la citada irrupción de las apuestas y juegos a través de internet y al verse superados los límites territoriales de las relaciones comerciales tradicionales, la doctrina del Tribunal de Justicia de la Unión Europea ha señalado la necesidad de establecer una oferta dimensionada de juego. En paralelo a este proceso de cambio, han aparecido nuevos operadores en el mercado del juego para los que la normativa vigente no ofrece una respuesta regulatoria adecuada. La carencia de los instrumentos normativos adecuados para dar respuesta a los interrogantes creados ante la nueva situación del mercado, ha generado en el sector del juego la necesidad de establecer nuevos mecanismos de regulación que ofrezcan seguridad jurídica a operadores y participantes en los diferentes juegos, sin olvidar la imprescindible protección de los menores de edad, de aquellas personas que hubieran solicitado voluntariamente la no participación, así como la protección del orden público y la prevención de los fenómenos de blanqueo de capitales y financiación del terrorismo.

3 Antes de entrar en el fondo de la cuestión, resulta necesario señalar que el juego de azar (Álea) es uno de los cuatro grupos que Caillois (1986) distinguía entre los juegos. Los tres restantes son: los de competición (Agón), los de representación (Mimicry) y los de vértigo (Ilinx). 
total y absoluto los límites que la legislación había establecido. Además, a pesar de alcanzar ésta una extensión difícilmente superable, los poderes públicos han sido incapaces de regular con eficacia las actividades que las nuevas tecnologías permiten y se han limitado a repetir o reproducir, de forma más o menos machacona, los parámetros que se habían establecido en febrero de 1977, cuando la situación política y tecnológica era muy diferente.

De hecho, hace ya muchos años, un editorial de la revista Álea, órgano del Centro de Estudios de Legislación sobre el Juego (1995), una entidad privada e independiente, calificaba la situación legislativa de este sector como de "esclerosis normativa": "Debemos afirmar que el ordenamiento regulador del juego de azar en España comienza a mostrar preocupantes síntomas de esclerotización, hasta el punto de que, tras un atento estudio, si un analista aplicara los métodos científicos tradicionales, no podría constatar la correspondencia entre las normas y los fines que estas pretenden cumplir ni en algún caso si sirven a algún fin, al menos de interés general”. En suma, no se atisba coherencia alguna sino puro mecanismo de reproducción normativa, lo cual no tiene nada que ver con el verdadero sentido de regular, medir o ajustar algo, o sea, poner en orden.

Es cierto que si el editorial giraba principalmente sobre la esclerotización de las normas tributarias “debido a dos factores: envejecimiento y 'abuso de grasa' (atención prioritaria a la finalidad recaudatoria), no lo es menos que el resto del ordenamiento del juego también necesita[ba] retoques de alguna importancia”. Se preguntaba entonces el editorialista -nótese que hablamos de 1995- cómo se iban a regular las ventas de loterías y apuestas en España cuando se vendiesen en nuestro país las de otros miembros de la Unión Europea. O, más aún, cuando ocurriera algo parecido pero por una oferta interna en el mercado nacional. También preocupaba el "efecto frontera" causado por el ejercicio de su competencia por cada Comunidad Autónoma, así como la desaparición de la unidad del mercado interior, sin olvidar todos los aspectos referentes al juego por internet.

He recogido este testimonio, hecho público hace aproximadamente 17 años, por dos razones principales: por un lado, porque vio la luz justo a la mitad de los 35 años que llevamos en España con el juego de azar permitido (y ya entonces parecía que la legislación aplicable no daba mucho más) y, en segundo lugar, porque rápidamente se constató que pese a que se esgrimieron todo tipo de razones éticas y morales (y que todavía hoy salieron a la luz en la exposición de motivos del Proyecto de Ley de Regulación del Juego), el verdadero leit motiv de la normativa era de tipo fiscal y claramente recaudatorio. Hace 17 años se denunciaba que "se acumulan tributos en catarata: tasa de juego, gravámenes complementarios retroactivos de grado medio, eso sí, de los cuales el sector ya ha sufrido dos hasta ahora (el primero de ellos era "extraordinario"), impuestos de actividades económicas duplicados y triplicados cuando casinos, bingos y salones recreativos tienen máquinas instaladas, recargos sobre la tasa de juego e impuestos propios de las Comunidades Autónomas (CCAA), "ponderadas" tasas por tramitaciones de las docenas de autorizaciones y comunica- 
ciones necesarias para desenvolver la actividad, el IVA soportado y no repercutible, y todavía algún ayuntamiento establece tasas de policía. Esta catarata tributaria se ha convertido ya en un impuesto "tala", al que se refería el profesor Luigi Einaudi, impropio de las nuevas concepciones de la doctrina tributarista.

Esta situación, tan significativamente descrita en 1995, se correspondía con una coyuntura que palpablemente demostraba las carencias de una verdadera política pública del juego positiva, ordenada, coordinada y lógica; es decir, con respuestas a los problemas/oportunidades sociales no retardados. En otro lugar he señalado, de acuerdo con la opinión de Dye (1992), que el proceso de formulación, ejecución y puesta en práctica de las decisiones que el gobierno adopta respecto de un tema concreto (en nuestro caso, evidentemente, el juego de azar) comporta, asimismo, la decisión de no hacer algo o de hacerlo parcialmente. El hecho de no intervenir implica adoptar una posición concreta y clara, por mucho que se justifique poniendo sobre el tapete -nunca mejor dicho- razones que expliquen la inactividad gubernamental. Así lo manifesté con ocasión de un seminario organizado por la Fundación Codere en los cursos de verano de la Universidad Internacional Menéndez Pelayo en Sevilla: "se debe ser consciente, desde un principio, que el no hacer supone obtener unos resultados determinados diferentes a los que se alcanzarían si se adoptasen decisiones y, por lo tanto, el no hacer supone aceptar una opción y apostar por ella" (Cases, 2009: 16-19). En pocas palabras, la inacción tiene tantas consecuencias como la acción. Y, en este caso, la inacción ha tenido efectos perversos sobre el sistema.

\section{APUNTE HISTÓRICO: DE LA PENALIZACIÓN A LA DESPENALIZACIÓN PARCIAL}

Tracemos un rápido recorrido histórico que nos lleve inicialmente a la Edad Media. En España, la primera regulación que se cita es la contenida en las Partidas (12561265) de Alfonso X el Sabio, que decretaron la persecución de los tahúres y establecieron penas para el que tuviera en su casa "tablero para jugar dados o naipes". Le siguió el Ordenamiento de Tafurerías (casas de juego) de 1314, la disposición de don Alonso, en Madrid, en 1329, y el Ordenamiento de Alcalá de 1348, que en su artículo 31 de la Ley I prohibía el juego de dados y tablas a dinero y sobre prendas a los militares durante la guerra y en servicio.

Años más tarde, en 1387, Juan I de Castilla, en su Ley 22 (que posteriormente fue ratificada por los Reyes Católicos en Madrigal), comenzó un iter legislativo consistente en penalizar el juego al establecer que "mandamos y ordenamos, que ninguno de los de nuestros reynos sean osados de jugar dados ni naypes en público ni en escondido; y cualquier que los jugare por la primera vez pague seiscientos maravedís, y por la segunda mil y doscientos maravedís, y por la tercera, mil y ochocientos maravedís, y dende en adelante por cada vez tres mil maravedís y si no hobiere de que los pagar, que yagan por la primera vez diez días en la cadena, y por la segunda veinte días y por 78 la tercera treinta días y así dende en adelante por cada vez, no teniendo de que pagar 
los dichos maravedís, esté preso treinta días”. Durante seiscientos años la percepción peyorativa del juego se ha mantenido constante.

En esa misma Ley se introduce también el principio de la inexigibilidad de las deudas de juego: "y mandamos, que aquel que alguna cosa perdiere que lo pueda demandar a quien se lo ganare hasta ocho días y el que lo ganare sea tenido de tornar lo que así ganare; y si el que perdiere hasta ocho días no lo demandare que qualquier que se lo demandare lo haya para sí, y si alguno no lo acusare ni demandare que qualquier juez o alcalde de su oficio, sabiéndolo, lo execute y sea para la nuestra Cámara; y si así no lo hiciere el Juez, pague seiscientos maravedís, la mitad para el que lo acusare y la otra mitad para la Cámara". En cierto modo, lo aquí dispuesto se ha mantenido hasta el vigente Código Civil, en los artículos que van desde el 1798 al 1801, tal como señala López Maza (2011).

Gran parte de los monarcas españoles tomaron medidas relativas al juego de azar, lo que da buena medida de la importantica de la actividad. El rey Juan II dictó normas en Zamora, en 1432, sobre el monopolio del juego en los pueblos que tenían por privilegios las rentas de los tableros; en 1480, los Reyes Católicos recordaron las leyes prohibitivas que, por medio de la Pragmática dictada en Granada en 1499, las desarrollaron estableciendo el procedimiento de ejecución por parte de los jueces de las penas que recaían sobre los juegos prohibidos y sobre los arrendadores de tableros.

En 1515, en Burgos, el rey Fernando y su hija doña Juana promulgaron una Pragmática sobre la prohibición de fabricar y vender dados y de jugar con ellos. Posteriormente, el emperador ratificó dicha Pragmática. Asimismo, Juana, junto con su hijo Carlos (el emperador Carlos V, que reinó en España con el título de Carlos I), establecieron en 1528 la prohibición de jugar a crédito y fiado, y la nulidad de la obligación que contra esto se hiciere.

Corría la mitad del siglo, era 1553, cuando en Valladolid, doña Juana, el emperador y el entonces príncipe Felipe regulan "el modo y la cantidad que se puede jugar el juego de pelota y otros juegos permitidos y no al fiado”. Pocos años más tarde, siendo ya rey, en 1568, Felipe II estableció nuevas penas "a los que hicieren, tengan o jueguen dados" y extendió estas penas en 1575 al juego de “carpeta”. En 1586 amplió la penalización a los juegos de "bueltos, bolillos, trompico, palo y otros".

Dos siglos más tarde, poco había cambiado sobre la percepción social del juego: Carlos III, ante la afición generalizada de sus súbditos por los juegos de azar, dictó en 1771 una Pragmática prohibiendo a "los estantes en estos reynos" sin distinción de clases (pues sus antecesores en la dinastía ya habían derogado cualquier fuero privilegiado en esta materia y habían sometido a los contraventores a la justicia ordinaria) que jueguen, tengan o permitan en su casa los juegos de "banca, faraón, baceta, carpeta, banca fallida, saca mete, parar, treinta y cuarenta, cacho, flor, quince, treinta y una envidada, ni otros cualesquiera de naipes que sean de suerte o azar y que se jue- 
guen a envite, aunque sean de otra clase y no vayan aquí especificados; como también los juegos del birbis, oca o auca, dados, tablares, azares y chuecas, bolillo, trompico, palo o instrumento de hueso, madera o metal, y de otra manera alguna que tenga encuentros, azares o reparos; como también el de taba, cubiletes, dedales, nueces, correguela, descarga la burra y otros cualesquiera de suerte o azar aunque no vayan señalados con sus propios nombres".

Durante su reinado, el secretario de la Real Hacienda, el marqués de Esquilache, introdujo una lotería de influencia centroeuropea "para beneficio de hospitales, hospicios y obras pías y públicas, en que se consumen anualmente muchos caudales de mi Real Erario". Se le llamó Lotería Primitiva o Lotería de Números (muchos años más tarde, cuando se introdujo su versión moderna, en 1985, no faltaron referencias históricas a estos sus orígenes).

El sucesor de Carlos III, Carlos IV, firmó la Real Orden de 6 de abril de 1800, que, en el mismo sentido de muchas anteriores, prohibía el juego de la lotería de cartones en los cafés y casas públicas (en este caso, precedente remoto, como señala José Ramón Romero, del juego del bingo) ${ }^{4}$.

Finalmente, en 1811, para ayudar a sufragar los gastos de la Guerra de la Independencia, el Ministro del Consejo y Cámara de Indias, González Carbajal, proyectó introducir en España una lotería de billetes como la que ya existía en Nueva España. Las Cortes de Cádiz aprobaron su propuesta el 23 de noviembre de 1811, El primer sorteo se celebró el 4 de marzo de 1812. Es la Lotería Nacional o Lotería Moderna.

Así pues, el juego de azar, tanto por razones sociales como morales, ha provocado el rechazo de los gobernantes y de la sociedad española en general, al mismo tiempo que ha obligado a los monarcas a regularlo. Ya hemos señalado cómo desde Alfonso X el Sabio los sucesivos reyes hicieron saber, a través de numerosas disposiciones, cuál era su percepción acerca de la práctica de los juegos de azar y ordenaron, por lo tanto, su persecución.

Esta larga tradición de percepción negativa del juego logró calar en la cultura política de la sociedad española hasta bien entrado el siglo XX. Debido a esta visión normativa prohibicionista, la opinión pública contemplaba el juego como contenedor y origen de disfunciones importantes, tanto externas, que se derivaban de la prohibición de la actividad y por tanto eran la causa de ilegalidad y delito, como internas, porque también era percibido como un elemento que socavaba los valores morales de la sociedad y conducía a la adicción (ludopatía).

Por eso no puede extrañarnos que en tiempos mucho más próximos el general Primo de Rivera fuera quien decidiera incriminar la actividad del juego de azar, prohi-

4 Todos los datos recopilados en este apartado provienen de la intervención de José Ramón Romero en el Seminario sobre El Juego de Azar y la Sociedad Española, celebrado durante los cursos de verano 80 "La normativa de los juegos de azar. Derecho interno y referencias a normativa de la Unión Europea". 
biendo su práctica, cerrando los casinos existentes y configurando un tipo penal para impedir su desarrollo. Para ello utilizó el texto del Código Penal de 1928, de corta vida, ya que fue anulado por la República, que restauró el de 1870, surgido de nuestra Gloriosa. No obstante, de hecho, Primo de Rivera no alteró sustancialmente el estado de cosas, ya que en 1922, un año antes de su llegada al poder, se cerraron 2.000 salas de juego, por lo que se decidió que la mejor forma de controlarlo era radicalizar la postura y prohibirlo completamente.

La Segunda República Española y el régimen del general Franco (durante el cual rige el Código penal de 1944, texto revisado de 1963 y texto refundido de 1973) mantuvieron la prohibición, a pesar de varios intentos en sentido contrario. El más sonado por las consecuencias negativas que affaire produjo fue el que derivó en el escándalo reconocido bajo la denominación de "estraperlo", que provocó en 1935 la caída del quinto y último gobierno Lerroux. Su origen se halla en el soborno a varios funcionarios por parte de tres empresarios, uno de ellos apellidado Strauss y el otro Perl-de ahí el nombre con el que se conoció el escándalo-. Los empresarios se beneficiaron de la instalación de unas ruletas trucadas en el Casino de San Sebastián y en el Hotel Formentor (Mallorca). Esta ruleta estaba controlada mecánicamente de tal forma que la banca se aseguraba las peripecias de la bola y en definitiva el resultado del juego.

Así las cosas, antes de restaurarse plenamente el sistema democrático y aprobarse la Constitución de 1978, aunque ya iniciada la Transición, se pretendió llevar a la práctica lo que en frase feliz de Adolfo Suárez se compendiaba en "hacer normal en política lo que es normal en la calle". De modo que se dieron los primeros pasos, tímidos y titubeantes, para despenalizar parcialmente la práctica del juego de azar, mediante el Real Decreto-Ley 16/1977, de 25 de febrero, que regula los aspectos formales, administrativos y fiscales de los juegos de suerte, envite o azar y las apuestas. Este RDL apareció con una finalidad primordial: atemperar el régimen establecido por los artículos 349 y 350 del Código penal y permitir la práctica de los juegos de casino, así como del bingo y de las máquinas recreativas, que ya habían alcanzado por la vía de los hechos consumado una importante extensión en todo el país.

La exposición de motivos, en su primer párrafo, planteaba ya con crudeza y total claridad cuál era el estado de la cuestión y las razones por las que por vez primera la Administración había decidido intervenir en un campo tan vidrioso y discutido: "Aunque no ha cambiado sustancialmente ni en España ni en otros muchos países las concepciones generales en torno a los juegos de azar y a sus posibles consecuencias individuales, familiares y sociales no se puede desconocer que los sistemas de prohibición absoluta frecuentemente han fracasado en la consecución de sus objetivos normalizadores y se han convertido de hecho en situaciones de tolerancia o de juego clandestino generalizado, con más peligros reales que los que se trataban de evitar y en un ambiente de falta de seguridad jurídica".

En suma, el rechazo social y las consecuencias indeseables (personales y familiares) eran los motivos esgrimidos para su antigua prohibición. La prohibición tenía una 
vocación normalizadora, pero evidentemente, dado el éxito de las practicas y su extensión entre todos los estratos sociales, no cupo menos que reconocer que la estrategia prohibicionista había fracasado, porque bien por la tolerancia ante el incumplimiento de la ley, bien por la extensión generalizada de determinados juegos, se había demostrado la ineficacia del sistema de prohibición absoluta.

No obstante, siendo todo esto cierto, no es toda la verdad. Solo en el segundo párrafo de la exposición de motivos se dejaba entrever las "nuevas razones" más acordes con los "nuevos tiempos" que aconsejaban proceder a su regulación. "La renovación general de pautas de comportamiento colectivo que se está produciendo en el país, de un lado, y del otro la contemplación de las experiencias positivas consagradas, en material específica de juegos, en otros países geográfica o culturalmente próximos al nuestro, induce a iniciar nuevos derroteros en este campo, con objeto de asegurar con más eficacia el cumplimiento de objetivos ineludibles de tutela y protección social, al propio tiempo que se logra importantes finalidades complementarias de interés social y de defensa y fomento de intereses fiscales...". En otras palabras, los nuevos tiempos traen consigo nuevas costumbres y aunque pervive el interés social de proteger a los miembros de la comunidad de los peligros que una actividad nociva comportan, no por ello debe dejar de contemplarse la no menos importante defensa y fomento de los sistemas fiscales. Esta variable, la recaudatoria, va a marcar el devenir de la regulación del juego en España.

EI RDL de 1977 eliminó la penalización existente, sustituyéndola por la autorización administrativa previa a favor de los juegos de casino, así como el del bingo y las máquinas recreativas, reservándose el Estado el establecimiento de las reglas que, a través de los poderes públicos, iban a marcar el campo permisivo del juego de azar.

A partir de ese momento (febrero de 1977), en las políticas públicas desarrolladas por los gobiernos tanto del Estado como los autonómicos han ido siempre de la mano las razones morales y los criterios -o quizás, mejor dicho, necesidades- fiscales del Estado, decantándose finalmente, con el paso de los años, en favor de estos últimos las acciones gubernamentales. Ello ha conducido a un curioso cambio de orientación de las políticas públicas que ha pasado de la coerción y obligatoriedad primitiva, señalando mediante la coacción una obligada conducta (Vallés, 2003: 378), a mantener un statu quo tendente a una tutela formal pero no real del juego de azar. La plasmación más reciente de esta visión es ley que acaba de tramitarse en las Cortes Generales y que justifica estas páginas.

\section{3. ¿CUÁLES SON LOS JUEGOS DE AZAR PERMITIDOS?}

Históricamente, el Estado explotaba las loterías (primitiva y moderna) así como las Apuestas Mutuas Deportivo-Benéficas. De las primeras, y concretamente sobre su creación, ya hemos hablado y no es necesario detenerse en la importancia que la lo-

82 tería ha alcanzado en España. Por su parte, las apuestas deportivas, y en principio la 
más popular, la quiniela, se derivan de la creación, por Decreto-Ley de 12 de abril de 1946, del Patronato de Apuestas Mutuas Deportivo-Benéficas. Las quinielas se implantan a partir del 22 de septiembre del mismo año; el $45 \%$ de lo recaudado se destina a premios y el otro $45 \%$ va a parar conjuntamente a las arcas de las diputaciones provinciales, (en orden al cumplimiento de sus fines benéficos) y de la Dirección General de Beneficencia y Obras Sociales del Ministerio de la Gobernación.

En otro plano se sitúa el cupón de la Organización Nacional de Ciegos de España (ONCE). En el preámbulo del Acuerdo General firmado entre el Gobierno y la ONCE, que data de 1999, se declara que el peso de la financiación de esta última recae fundamentalmente sobre los recursos provenientes del cupón pro-ciegos, calificado como una modalidad de la Lotería del Estado explotada por una Corporación de Derecho Público con carácter social.

Además de estos juegos públicos, como ya se ha indicado, a partir de 1977 se permitieron los que se dio en llamar juegos privados, que realmente eran juegos de azar permitidos con gestión privada. Un primer grupo de ellos queda englobado en la expresión genérica de "juegos de casino". Un casino es el "establecimiento dedicado especialmente a las prácticas de juegos de suerte, envite o azar de los incluidos en el Catálogo de Juego", según la definición artículo 1 de la Orden ministerial (OM) de 9 de enero de 1979 del Ministerio del Interior.

El bingo es el segundo juego autorizado. Según el artículo 100 de la OM de 9 de octubre de 1979, es "una lotería jugada sobre 90 números, del 1 al 90 inclusive, teniendo los jugadores como unidad de juego cartones o tarjetas integradas por 15 números distintos entre sí, y distribuidas en tres líneas horizontales de cinco números cada una y en nueve columnas verticales, en cualquiera de las cuales puede haber, tres, dos o un número pero sin que nunca haya una columna sin número".

Finalmente se autorizaron también las máquinas recreativas, que son aquellas que por un determinado importe conceden a los usuarios un tiempo de uso de juego y, eventualmente, un premio en dinero (artículos 4 y 5 del Real Decreto 2110/1998, de 2 de octubre). En líneas generales, existen (porque en la actualidad hay CCAA que establecen nuevas subdivisiones) tres clases principales de máquinas: las simplemente recreativas, o de tipo A, (que ya estaban autorizadas), que no dan ningún premio en metálico, ni en especie, ni en puntos canjeables por objetos o dinero, es decir, son simplemente de puro entretenimiento. Por ejemplo las denominadas flipper. En segundo lugar, las máquinas recreativas con premio programado, o de tipo B (las conocidas como tragaperras). Por último, las de casino o azar (tipo C). En esta clase el premio depende únicamente del azar.

\section{EVOLUCIÓN TEMPORAL DE LA PERCEPCIÓN POLÍTICA DE LAS COMUNIDADES SOBRE EL JUEGO}

Resulta revelador, como muestra de las políticas públicas que se han ido aplicando en cada momento, el cambio de terminología que se refleja en las exposiciones de 
motivos de las leyes autonómicas del juego respecto de la que acompaña al citado RDL de 1977. Si bien no hay exposición de motivos en la primera de las leyes autonómicas, que en una sucesión cronológica es la que corresponde a Cataluña (Ley 15/1984, de 20 de marzo), en otras, como en la de Galicia (Ley 14/1985, de 23 de octubre), se reconoce que el juego es "una manifestación más del desarrollo de la libertad individual" aunque "sin embargo no solo por la incidencia que el juego tiene en la conducta ciudadana y en la moral social sino incluso por ser una importante fuente de ingresos para el erario público" debe tener una regulación y control adecuados "cuando excede los límites del simple ocio".

Poco tiempo después, la Comunidad Valenciana, en la Ley 4/1998, de 3 de junio, manifiesta "no querer ignorar el hecho social del juego legalizado", entendiendo por este no la actividad recreativa o lúdica sino "la modificación patrimonial en cuanto designio del azar”. Por ello se justifica la intervención pública que module la reacción habida con motivo del "levantamiento de la absurda prohibición del juego", que el legislador califica como "pretensión liberalizadora sin reservas”.

Los toques de realismo se producen a partir de la Ley que regula el juego en el País Vasco, ley 4/1991, de 8 de noviembre. El sector del juego es considerado "como una parte del entramado económico vasco" $y$, si bien "se protegen los derechos de los menores de edad y de las personas que tengan reducidas sus facultades volitivas impidiendo su participación en el desarrollo de los juegos de los que resulte la obtención de premios", se establece "un ámbito normativo sin pretensión de limitar el juego ni impedirlo".

Como último botón de muestra, cronológicamente hablando, la Ley Foral de Navarra 16/2006, de 14 de diciembre (que sustituyó a la Ley Foral 11/1989, de 27 de junio), compara la situación con la existente 17 años atrás, reconociendo que "a lo largo de los últimos años el juego se ha mostrado como un sector de la actividad económica dotado de un gran dinamismo. La innovación tecnológica, las oportunidades de negocio que genera, la desaparición de fronteras económicas, la globalización y el desarrollo de la sociedad de la información -especialmente las posibilidades que derivan de la utilización de la telefonía, Internet y el correo electrónico, así como las prácticas seguidas en determinados formatos televisivos- han hecho que el juego haya evolucionado rápida y expansivamente hacia nuevas formas y modos de practicarlo, que han calado rápidamente entre los jugadores, hasta el punto de que hoy se puede apreciar un escenario social en el que los medios y la oferta de alternativas para jugar es diversa y prolija y en el que, en ocasiones, atendida la posibilidad de participar en juegos y apuestas reales o virtuales organizados fuera de los ámbitos de regulación, resulta difícil preservar aquellos valores e intereses antes aludidos"

5 Mientras se revisaba este artículo, el Diario de Noticias de Navarra en su edición de 10 de abril de 2011, informaba, junto con otros medios, que los navarros se han gastado en seis meses cinco millones de euros en las nuevas máquinas de apuestas deportivas. 


\section{LA DISTRIBUCIÓN TERRITORIAL DE LAS COMPETENCIAS DE JUEGO}

En un principio, las competencias sobre juego fueron ejercidas por la Comisión Nacional del Juego, como órgano de coordinación, estudio y control de las actividades relacionadas con los juegos de azar. De este modo, la Comisión Nacional del Juego asume la función de homologación de material de juego (RD 444/1977 de 11 de marzo). Al año siguiente, mediante RD 2709/1978, de 14 de octubre, se modificaron los dos decretos precedentes, reconociéndose en su preámbulo que las normas anteriores se habían dictado con excesiva premura. Por tanto, no se habían contemplado una serie de problemas existentes en ese momento debido a la falta de experiencia regulatoria de la Administración en esta materia y también por la gran evolución producida en el sector del juego desde un primer instante. Entre las disposiciones que se adoptaron se encuentra la modificación de la composición y competencias de la Comisión Nacional del Juego, adscribiéndola al Ministerio del Interior (existía a este respecto una laguna legal, porque cuando fue creada no se había adscrito a ningún Ministerio). La presidía el subsecretario de Interior y la componían 11 vocales representantes de los ministerios de Economía y Hacienda, Trabajo y Asuntos Sociales, Educción y Cultura e Interior. El secretario general técnico de este último departamento ejercía como secretario.

El ingente trabajo de autorizaciones y homologaciones aconsejó crear un órgano de apoyo a la Comisión, pues por el carácter intermitente de sus reuniones se precisaba de un equipo que preparase la documentación, despachara los asuntos que no requiriesen de aprobación de la Comisión y ejecutase los acuerdos de ésta. El RD 1086/78, de 2 de mayo, creó el Gabinete Técnico de la Comisión Nacional del Juego, con nivel de Subdirección General y dependiente de la Subsecretaría de Interior; su jefe sería el secretario de la Comisión.

También por RD 901/1990, de 13 de julio, se le reconoció al Gabinete Técnico el nivel de Dirección General y, en 1993, éste desaparece como centro directivo al haberse transferido a todas las Comunidades Autónomas las competencias exclusivas sobre el juego y reestructurarse el Ministerio de Interior, asumiendo de nuevo los fines y competencias del Gabinete extinto, la Secretaría General Técnica del Ministerio del Interior. Este régimen de organización llega hasta nuestros días, si bien, como se ha subrayado, el Ministerio ha perdido prácticamente todas sus competencias transferidas en bloque a las Comunidades Autónomas.

Las Comunidades que accedieron a la autonomía por la vía del artículo 151 de la Constitución tuvieron la posibilidad de asumir aquellas materias que no habían sido atribuidas expresamente al Estado. Por esta razón, los cuatro primeros Estatutos (Cataluña, País Vasco, Galicia y Andalucía) se atribuyeron la competencia sobre casinos, juegos y apuestas, con exclusión de las Apuestas Mutuas-Deportivas Benéficas.

Ya sabemos que la Comunidad Valenciana y las Islas Canarias lograron, a pesar de acceder a la autonomía por la vía del artículo 143, obtener competencias comple- 
mentarias a las reconocidas por sus Estatutos en virtud del artículo 150 de la Constitución, equiparándose al techo competencial de las llamadas "comunidades históricas" por las Leyes Orgánicas (LO) 10/82 y 11/82 respectivamente. En virtud de ellas, fueron plenamente competentes en materia de juegos de azar y apuestas, con la excepción señalada de las Apuestas Mutuas-Deportivo Benéficas. Navarra constituyó otra excepción, ya que por la LO 13/82, de 10 de agosto, de Reintegración y Amejoramiento del Fuero, asumió como competencia exclusiva las materias de juego.

En 1978, el constituyente no estableció nada respecto de la competencia estatal en materia de juego de suerte, envite y azar, facilitando con ello, en razón de lo establecido en el artículo 149.3 de la Carta Magna, el traspaso de competencias a las Comunidades Autónomas, que, a medida que se iban constituyendo, reclamaban para sí la competencia exclusiva. Porque si bien, como ha señalado Fernández Allés (2002: 264) "no podemos identificar propiamente un modelo español de reparto de competencias ejecutivas sí que existen, en cambio, unos elementos que singularizan un método de distribución de funciones" cuya primera nota característica es la exigencia en mantener la unidad de las políticas públicas.

En el cuadro 1 se refleja tanto el artículo de los Estatutos de Autonomía correspondientes en los que establece la competencia exclusiva como el RD de transferencia y la ley de juego autonómico que la desarrolla.

\section{CUADRO 1}

Desarrollo de la normativa sobre juego en las Comunidades Autónomas

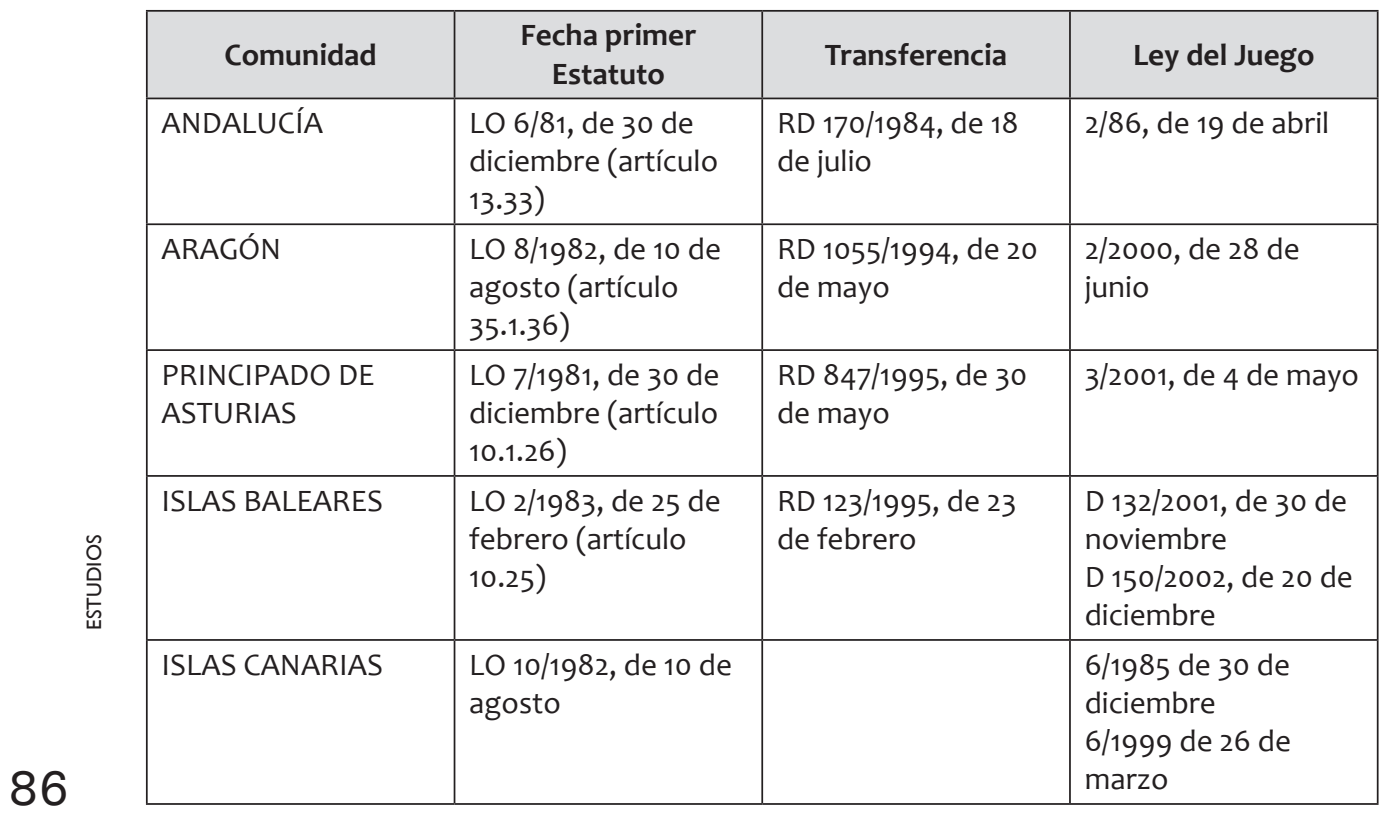




\section{CUADRO 1}

Desarrollo de la normativa sobre juego en las Comunidades Autónomas

\begin{tabular}{|c|c|c|c|}
\hline Comunidad & $\begin{array}{l}\text { Fecha primer } \\
\text { Estatuto }\end{array}$ & Transferencia & Ley del Juego \\
\hline CANTABRIA & $\begin{array}{l}\text { LO 8/1981, de } 30 \text { de } \\
\text { diciembre (artículo } \\
24.25 \text { ) }\end{array}$ & $\begin{array}{l}\text { RD } 1387 / 1996 \text {, de } 7 \\
\text { de junio }\end{array}$ & $\begin{array}{l}4 / 1998 \text {, de } 2 \text { de } \\
\text { marzo } \\
\text { 15/2006, de } 24 \text { de } \\
\text { octubre }\end{array}$ \\
\hline CASTILLA Y LEÓN & $\begin{array}{l}\text { LO } 4 / 1983 \text {, de } 25 \text { de } \\
\text { febrero }\end{array}$ & & $\begin{array}{l}\text { 4/1998, de } 26 \text { de } \\
\text { junio }\end{array}$ \\
\hline $\begin{array}{l}\text { CASTILLA-LA } \\
\text { MANCHA }\end{array}$ & $\begin{array}{l}\text { LO 9/1982, de } 10 \text { de } \\
\text { agosto (artículo } \\
\text { 31.1.21) }\end{array}$ & $\begin{array}{l}\text { RD 377/1995, de } 10 \\
\text { de marzo }\end{array}$ & $\begin{array}{l}\text { 4/1999, de } 31 \text { de } \\
\text { marzo }\end{array}$ \\
\hline CATALUÑA & 1979 (artículo 9.32) & & $\begin{array}{l}\text { 15/1984, de } 20 \text { de } \\
\text { marzo* }\end{array}$ \\
\hline EXTREMADURA & $\begin{array}{l}\text { LO } 1 / 1983 \text {, de } 25 \text { de } \\
\text { febrero (artículo } 7 \text { ) }\end{array}$ & & $\begin{array}{l}\text { 6/1998, de } 18 \text { de } \\
\text { junio }\end{array}$ \\
\hline GALICIA & $\begin{array}{l}\text { LO 1/1981, de } 6 \text { de } \\
\text { abril (artículo 27) }\end{array}$ & $\begin{array}{l}\text { RD 228/1985, de } 6 \text { de } \\
\text { febrero }\end{array}$ & $\begin{array}{l}\text { 14/1985, de } 23 \text { de } \\
\text { octubre }\end{array}$ \\
\hline $\begin{array}{l}\text { COMUNIDAD DE } \\
\text { MADRID }\end{array}$ & $\begin{array}{l}\mathrm{LO} 3 / 1983 \text {, de } 25 \text { de } \\
\text { febrero (artículo } \\
26.1 .29 \text { ) }\end{array}$ & $\begin{array}{l}\text { RD } 2370 / 1994 \text {, de } 9 \\
\text { de diciembre }\end{array}$ & 6/2001, de 3 de julio \\
\hline REGIÓN DE MURCIA & $\begin{array}{l}\text { LO } 4 / 1982 \text {, de } 9 \text { de } \\
\text { junio }\end{array}$ & & $\begin{array}{l}\text { 2/1995, de } 16 \text { de } \\
\text { marzo }\end{array}$ \\
\hline NAVARRA & $\begin{array}{l}\text { LO 13/1982, de } 10 \text { de } \\
\text { agosto (artículo } \\
44.16 \text { )** }\end{array}$ & & $\begin{array}{l}\text { 11/1989, de } 27 \text { de } \\
\text { junio } \\
16 / 2006 \text { de } 14 \text { de } \\
\text { diciembre }\end{array}$ \\
\hline PAÍS VASCO & $\begin{array}{l}\text { LO 3/1979, de } 18 \text { de } \\
\text { diciembre (artículo } \\
\text { 10.35) }\end{array}$ & & $\begin{array}{l}\text { 4/1991, de } 8 \text { de } \\
\text { noviembre }\end{array}$ \\
\hline LA RIOJA & $\begin{array}{l}\text { LO 3/1982, de } 9 \text { de } \\
\text { junio (artículo } 8 . \\
\text { uno.10) }\end{array}$ & $\begin{array}{l}\text { RD } 2376 / 1994 \text {, de } 9 \\
\text { de diciembre }\end{array}$ & 5/1999, de 13 de abril \\
\hline $\begin{array}{l}\text { COMUNIDAD } \\
\text { VALENCIANA }\end{array}$ & $\begin{array}{l}\text { LO 5/1982, de } 1 \text { de } \\
\text { julio }\end{array}$ & $\begin{array}{l}\text { RD } 1038 / 1985 \text {, de } 25 \\
\text { de mayo }\end{array}$ & 4/1998, de 3 de junio \\
\hline CEUTA & $\begin{array}{l}\text { LO } 1 / 1995 \text {, de } 13 \text { de } \\
\text { marzo }\end{array}$ & & \\
\hline MELILLA & $\begin{array}{l}\mathrm{LO} 2 / 1995 \text {, de } 13 \text { de } \\
\text { marzo }\end{array}$ & & \\
\hline
\end{tabular}

* Complementada por la Ley 1/1991, de 27 de febrero, de Régimen Sancionador en materia de juego.

** De Reintegración y Amejoramiento del Régimen Foral de Navarra.

Fuente: Elaboración propia. 


\section{EL EJERCICIO DE LAS COMPETENCIAS}

Como han señalado Bañón et al. (1997: 208), la principal característica del sistema español de relaciones intergubernamentales desde el inicio de la transición es la volatilidad. Desde 1977 hasta la actualidad podemos distinguir dos etapas:

a) Hasta 1992, año en que finaliza la transferencia de competencias a las Comunidades Autónomas. Se caracteriza sobre todo por la conflictividad con el Estado. El testimonio de Iglesias Díaz (1995: 124-125) resulta altamente revelador: "Muy a pesar del rechazo institucional mantenido desde la legalización del juego en España, acerca de no imitar el modelo americano en el contexto estructural legal del juego, y en consecuencia mantener una política unívoca sobre la materia en todo el Reino de España, lo cierto es que en la actualidad el mapa legislativo autonómico supera, con creces, la casuística de los Estados de la Unión, y aunque ello pueda reputarse como un grado de exageración, caminamos inexorablemente hacia un diseño sinuoso en la construcción de un puzzle autonómico, en el contexto legal de la actividad, cargado de excesivas marginaciones y especialidades que, lejos de incardinarse en una dirección armonizada u homogénea, se pronuncian claramente como una manifestación más de las diferencias regionales, tanto en el orden costumbrista como -quizá de manera más relevante- en el orden político, en función de la ideología de cada ejecutivo autonómico".

b) Desde 1992 hasta hoy. Durante estos 20 años las Comunidades Autónomas se dedican a regular de forma minuciosa hasta los más irrelevantes aspectos del juego (características de las máquinas, nuevos juegos que incorporan a su catálogo, prohibiciones varias, etc. $)^{6}$, pero desconocen, al igual que el Estado, la "desterritorialización” del juego, que es el fenómeno básico provocado por la aparición del juego on-line. Se genera un nuevo contexto y parecen repetirse algunos males, a los que hay que sumar la citada desterritorialización: se deja que la implantación del juego on-line se realice libremente sin que ningún nivel territorial se atreva a enfrentarse a su regulación, posiblemente como consecuencia del desgaste producido por la conflictividad de la primera etapa. Palomar Olmeda (2006: 87) resume muy gráficamente el proceso señalando que, por un lado "podemos indicar que nuestra historia reciente pasa de la ilegalización y la criminalización a la legalización en condiciones de sometimiento a autorización administrativa para el ejercicio de la actividad y la existencia de una fuerte reglamentación que afecta a todas las condiciones del ejercicio de la actividad"; pero, por otro, advierte: "Curiosamente la evolución normativa se ha centrado esencial-

6 Soriano Cabrera (2009: 118-119) afirma: “Es posible que, desde los años 80 hasta ahora, hayamos pecado todos y digo todos -Administración y sector privado- de un cierto exceso a la hora de reglamentar, quizá de una manera excesivamente intervencionista y explotar las determinadas ofertas de juego, llegando a concretar en legislaciones hasta cuestiones que se me antojaban, y se me antojan hoy, tremendamente exageradas". 
mente en una reglamentación autonómica y sin apenas regulación estatal más allá de la que procede la necesidad de adaptación constitucional de la potestad reglamentaria en materia sancionadora".

Durante estos años la Comisión Nacional del Juego siguió desarrollando sus funciones de gestión y mantuvo la competencia exclusiva a favor del Estado respecto de los territorios de las restantes Comunidades Autónomas mientras éstas no reclamaran su competencia exclusiva. Asimismo, se creó una Comisión Sectorial (integrada por el Estado y las Comunidades Autónomas con competencia exclusiva) para coordinar la política pública en estos territorios7. Sin embargo, a partir de la LO 9/92, de 23 de diciembre, se produjo la equiparación de competencias de las restantes Comunidades Autónomas, que habían accedido por la vía del artículo 143 a la autonomía, con las que ya detentaban las del artículo 151.

En 1999, la Comisión Sectorial se transformó en Conferencia Sectorial ${ }^{8}$ con el objeto de que fuese el órgano de coordinación y control entre todas las comunidades autónomas. Su fracaso en los primeros años fue espectacular, dado el grado de confrontación provocado por el distinto desarrollo e implementación de unas políticas públicas que en cada Comunidad Autónoma resultaron ser muy diferentes de las deseadas por el Estado. Solo se reunió una vez en los tres primeros años y fue con motivo de su sesión de constitución (González Gómez, 2006: 111).

Llegados a este momento debemos preguntarnos si al Estado le quedó alguna competencia (exclusiva, compartida o residual) tras las transferencias masivas realizadas por la LO 9/92, de 23 de diciembre. La respuesta no es fácil ni mucho menos puede ser clara, porque precisamente en este terreno discutido es donde, desde hace 20 años, ha transcurrido el debate y las batallas entre las Comunidades Autónomas y la administración central. Este conflicto ha conducido a situaciones graves y paralizantes que pretenden hoy ser solucionadas in extremis por la Ley de Regulación del Juego.

El debate se ha originado por una posición de partida de las Comunidades Autónomas, inamovible ya, que reclamaron que se entendiera que la competencia exclusiva era absolutamente excluyente y, por consiguiente, el Estado nada tenía que disponer en materia de juego, excepto para la Lotería Nacional y las Apuestas Mutuas Deportivo-Benéficas 9 . Las Comunidades Autónomas, erróneamente, entendieron

7 Según testimonio del entonces secretario general técnico del Ministerio del Interior, Rafael Ramos Gil, autoridad que había recibido, tras la desaparición del Gabinete Técnico de la Comisión Nacional del Juego, la gestión y ejecución de las competencias estatales, esta Comisión Sectorial "funcionó muy bien y se vio que era un instrumento útil de colaboración entre el estado y las CCAA".

8 Artículo 5 Ley 30/1992, de 26 de noviembre, de Régimen Jurídico de la Administración del Estado y Procedimiento Administrativo Común. El artículo 4 las perfila como un mecanismo orientado a "intercambiar puntos de vista y examinar en común los problemas de cada sector y las acciones proyectadas para afrontarlas y resolverlas".

9 Sirva como ejemplo la exposición del director general del Juego de Cataluña, Amadeu Farre i Morell (1995), “La organización de la Administración del Juego en España: presente y futuro. Las compe- 
que debían usar sus competencias para diferenciarse del Gobierno de España, mostrándose originales en la forma y fondo de regular los juegos. Incluso sobre el sorteo de la ONCE, Cataluña reclamó la posibilidad de su regulación, lo que fue denegado por el Tribunal Constitucional (STC 52/1988, de 24 de marzo, relativa al recurso de inconstitucionalidad planteado por el Estado ante determinados preceptos de la Ley Catalana 15/1984, de 20 de marzo, del Juego).

La zona de conflicto se amplió cuando el Estado, por razones diversas, fue tomando decisiones en materias de su competencia, pero que incidían, de un modo u otro, en el terreno del juego de azar. Podemos citar como ejemplo la fijación de las bases y coordinación de actividad económica general, la Hacienda General, el orden público, etc.

Al integrarse los ingresos de la lotería en la Hacienda Estatal, el Tribunal Constitucional se pronunció, entre otras, en la STC de 26 de mayo de 1994, reconociendo las competencias del Estado frente a las de las Comunidades Autónomas y negando que el primero resultara desapoderado frente a las competencias exclusivas para regular el juego: “... ni el silencio del artículo 149.1 de la Constitución respecto al juego, ni el hecho de que los estatutos de autonomía de algunas comunidades autónomas, entre ellas el de Cataluña, califiquen de exclusiva la competencia autonómica (excepto las Apuestas Mutuas Deportivo-Benéficas) puede interpretarse como equivalente a un total desapoderamiento del Estado, pues ciertas materias y actividades que bajo otros enunciados el artículo 149.1 CE reserva a aquel se encuentran estrechamente ligadas con el juego. Como reiteradamente tiene declarado este Tribunal, la calificación jurídica y el alcance de las competencias de las comunidades autónomas no puede hacerse derivar únicamente de una lectura aislada de la denominación que reciben en los textos estatutarios sino de una interpretación sistemática de todo el bloque de la constitucionalidad dentro del cual la Constitución conserva intacta su fuerza normativa dominante como lex superior de todo el ordenamiento, fuerza normativa que no se agota ni disminuye con la promulgación de los Estatutos de Autonomía, cuyos preceptos, por más que califiquen como exclusiva la competencia asumida, ratione materiae, no pueden oponerse a las normas constitucionales, que en su caso, reconozcan al Estado títulos competenciales sobre esa misma materia".

La falta de normas, instrumentos, organizaciones e instalaciones ha provocado un verdadero galimatías y frecuentemente una situación caótica en la aplicación de la política pública y no solo en la materia de juego. No es este el lugar ni el momento para realizar una crítica sobre el deficiente funcionamiento y coordinación de las administraciones públicas, resultado inevitable de un diseño autonómico muy superficial como es el contenido en el Título VIII de la Constitución Española.

tencias exclusivas. La coordinación entre las administraciones públicas" o la intervención del director general del Juego de Andalucía, Juan Antonio Serrano Cabrera (2006: 113-115) en el Seminario sobre la Industria del Juego, organizado por la Fundación Codere, en septiembre de 2006, durante los cursos de la Universidad Internacional Menéndez Pelayo en Sevilla. 
El hecho es que, como ya señaló Tomás Ramón Fernández (1996: 7), esto era lo esperable: "sin ninguna preocupación por la funcionalidad y coherencia del conjunto que de esa sustitución pudiera resultar. La planificación del juego por cada Comunidad Autónoma o la falta de ella ha contribuido a producir también efectos perversos que, ahora, una vez ultimado el proceso, deberían ser objeto igualmente de reconsideración".

Siguiendo a José Ramón Romero (1998: 7-10), indudablemente uno de los principales expertos jurídicos sobre el juego de azar entre los que desarrollan su trabajo profesional en España, se pueden señalar las diversas materias que necesariamente deberían ser objeto de coordinación y que al no serlo han causado las discrepancias y el caos actual. Entre ellas:

- La existencia misma del juego de azar (apuestas incluidas) cuya práctica rebasa el territorio no solo de una Comunidad Autónoma, sino incluso las fronteras nacionales.

- La obligación legal de garantizar la libre circulación de mercancías dentro de la UE así como la preservación del denominado principio de unidad de mercado (garantizado por el artículo 149.1.1 en relación a los artículos 38 y 139.2).

- La representación de España en los organismos internacionales de la materia (artículo $149.1 .3^{\circ}$ de la CE).

- La competencia del Estado en materia de seguridad pública (artículo 149.1.29) en coordinación con las policías autonómicas competentes.

- La estadística (artículo 149.1.31). Existen comunidades autónomas que se niegan a ofrecer sus datos lo que impide tener un conocimiento perfecto de realidad a nivel estatal.

- La normativa de los juegos del Estado (Loterías, Apuesta Deportivo-Benéficas) pero que incide de modo importante en el desarrollo de los juegos autonómicos.

- La regulación de la materia que incide tanto en la legislación civil (149.1.18 de la CE). (Un ejemplo es el registro de "autoprohibidos" que funciona en cada Comunidad Autónoma) como en la legislación mercantil (al establecer registros diferentes en cada territorio para gestionar los juegos, para contratar con la administración, etc.).

- La garantía del disfrute igual de derechos de todos los españoles en todo el territorio (149.1.1. en relación con el artículo 139).

- La potestad originaria a favor del Estado para el establecimiento de tributos (artículo 133.1 CE) con respecto a la potestad autonómica sobre la materia. 
Al no haber funcionado satisfactoriamente la Conferencia Sectorial del Juego, no ha existido una política pública homogénea, sino que se ha compartimentado en actuaciones diversas, originando normas técnicas cada día más divergentes.

Hasta aquí he tratado de demostrar, basándome en los textos citados, la realidad que se nos ofrece. Son las administraciones públicas las que han ido siempre a remolque en las medidas a adoptar (incluso, lo que no deja de ser llamativo, en las de contenidos fiscal). Es verdad que se ha legislado mucho y se ha producido una interminable serie de normas que ocupan más de 3.244 páginas en la última recopilación publicada (Palomar y Andrés, 2008), lo cual constituye una maraña administrativa que dificulta no solo la aplicación sino también el control, que es lo que en principio se persigue. De modo que desembocamos en lo que Freddi (1989) califica como ingobernabilidad. Además, tan incansable actividad normativa no significa que exista un criterio preciso que conduzca a desarrollar por cada gobierno competente una política pública sobre el juego de azar. Baste, por ejemplo, señalar que no se ha producido ninguna norma relativa a la prevención de la ludopatía ${ }^{10}$.

La última muestra de ir a remolque la constituye la iniciativa gubernamental de presentar el Proyecto de Ley de Regulación del Juego a las Cortes Generales ${ }^{11}$.

La potestad principal de las Comunidades Autónomas se refleja al asumir la responsabilidad de la organización -y por lo tanto del control- de los juegos de azar. Este hecho implica que las Comunidades Autónomas determinan cuál ha de ser el catálogo de juegos de la Comunidad (lo que algún Tribunal ha calificado como "potestad de regular la extensión y límites de la oferta") $)^{12}$.

Asimismo, tienen importancia capital todos los aspectos relacionados con los ingresos públicos. Por ello, se han creado nuevos juegos, tipo loterías y, se han fijado recargos fiscales. En esta materia se produce un choque frontal entre las Comunidades Autónomas y el propio Estado, interesado en que sus ingresos (vía lotería y apuestas y vía fiscal) no se vean mermados, pues como ha señalado Arnaldo Alcubilla (2004: 146), "la finalidad esencial de las loterías es obtener ingresos para el erario público"13.

10 Esta cuestión resulta llamativa y nos indica que en un Estado de Bienestar, el funcionamiento y rendimiento de los sistemas políticos debe medirse por la eficacia gubernamental que es la fuente de la legitimidad de ejercicio como ya señaló Lindblom (1991).

11 BOCG, Serie A. 11 de febrero de 2011. Núm. 109.1.

12 S.T. Superior de Baleares. Sentencia 912/2002 (Sala de lo Contencioso-Administrativo, sección única) de 8 de noviembre (RJCA, 2003: 358)

13 Otra opinión autorizada es la de López Nieto (2006: 177): “Es preciso considerar las implicaciones intergubernamentales del diseño de las distintas fuentes de financiación. Los sistemas de financiación subnacional combinan, en distintas proporciones, recursos procedentes de diversas fuentes entre las que se incluyen tributos propios de los gobiernos subnacionales, participación en tributos asignados a niveles superiores de gobierno, transferencias o subvenciones de naturaleza intergubernamental, ingre92 nos patrimoniales, así como recursos procedentes de la emisión de deuda o la suscripción de créditos. La 
El resultado final, sin ser catastrofistas, puede ser calificado de caótico. Porque, como ya se ha indicado, la conflictividad versa sobre las competencias (básicas para las comunidades autónomas puesto que de ella se derivan ingresos) y en el olvido de la realidad palmaria al no darse cuenta del nuevo aspecto que significa la no territorialidad del juego que contiene ofertas cada vez más atrayentes, tanto para las nuevas generaciones -que dominan la tecnología informática- como incluso para las personas de mayor edad que, aunque en porcentaje mucho más reducido, van incorporándose a este conocimiento y proveedor.

La no territorialidad lleva consigo la no presencia física del jugador y obliga a modificar de modo importante toda la normativa existente hasta el momento, tanto en lo que se refiere a las características técnicas del material del juego para ser homologado como lo relativo al estatuto del jugador (minoría de edad, registro de prohibidos, etc.). Resulta aconsejable, pues, que en este momento nos refiramos más detalladamente al juego por internet.

\section{JUEGO ON-LINE}

En 1995 se inicia el juego por internet. La entidad Internet Casino Inc. ofreció a partir del 18 de agosto de ese año 18 juegos de casino diferentes, así como el acceso on-line a la National Indian Lottery, según relata Carlos Lalanda (2006: 560). En la actualidad existen miles de páginas web dedicadas al juego.

Señala San Salvador del Valle (2010: 38) que "cuando hablamos de los juegos y las apuestas on-line nos estamos moviendo en un espacio intermedio en el que el mundo del ocio digital apoya al mundo del ocio físico, porque la actividad sobre la que se apoya tiene una naturaleza física, pero paulatinamente van a ir apareciendo expresiones separadas del mundo real. De igual manera que hay personajes dentro del ocio mediático que tienen identidad social propia, aunque nunca han existido (es el caso del Doctor House o Antonio Alcántara de la serie (uéntame), estamos asistiendo a un primer escenario en el que el juego digital se separe de la realidad y genere realidades desconocidas hasta el momento presente: ¿Nuevas experiencias de ocio? ¿Nuevas oportunidades de negocio?”

Podemos definir el juego on-line, en palabras de Carlos Lalanda (2010: 121) como "un amplio espectro de situaciones con trascendencia contractual que ocurren cuando una actividad relacionada con juegos de azar o apuestas son operadas a través de canales telemáticos como Internet (fundamentalmente), pero también y sin descartar las que se realizan a través de la TV interactiva, o del teléfono".

de financiación dan lugar a diferentes escenarios de relación intergubernamental, tanto desde un punto de vista general, esto es, considerando el sistema político-administrativo en su conjunto, como desde un punto de vista más específico, es decir, atendiendo a las distintas políticas públicas sectoriales y a los diversos territorios". 
Gusano Serrano (2010: 56) indica que "tras el estallido de la bomba digital han aparecido, y se han consolidado, nuevos espacios relativos al juego on-line, los gobiernos desean, y deben, controlar la falta de transparencia y seguridad en muchos aspectos, pero la propia naturaleza virtual de la Red dificultad, hasta límites insospechados, su control. El juego de azar por Internet se ha visto, y se verá aún más, beneficiado por el cambio en la conducta de los consumidores, quienes han ido modificando sus patrones de comportamiento, y de gasto, ante las diversas circunstancias sociales y económicas. La nueva tendencia es quedarse en casa en lugar de salir, ya que los consumidores buscan ahorrar dinero y tiempo, en su ocio y entretenimiento, en desplazamientos y otros gastos añadidos. El juego en línea -on-line- está perfectamente posicionado para sacar ventaja de esta tendencia y, también, para ofrecer la conveniencia, la variedad y el valor prioritario que los consumidores le dan al dinero y al tiempo en la actualidad".

A su vez, el Parlamento Europeo, en Resolución aprobada el 10 de marzo de 2009 sobre la integridad de los juegos de azar en línea, invita a los estados a controlar, supervisar y si fuera preciso limitar los servicios del juego de azar ${ }^{14}$.

La realidad, una vez más, ha atropellado al regulador y al legislador. No ha habido respuestas adecuadas a la rapidísima implantación y posterior expansión del juego on-line ${ }^{15} \mathrm{ni}$ a los nuevos aspectos que presentan juegos nominalmente iguales a los autorizados hasta el momento pero que resultan ser diferentes: inseguridad acerca de los actores (jugadores, empresarios), inseguridad acerca de las reglas del juego (participación, pago de premios), llamadas o sms por teléfono cuyo precio es por sí mismo una apuesta, etc.

Igualmente, la utilización de medios telemáticos tales como teléfono, televisión, Internet, etc. significa que los parámetros jurídicos por los que el juego presencial se rige, resultan ser muy distintos e inaplicables. Aspectos como el lugar en el que se supone se formaliza el contrato de juego, o cuándo el jugador presta su consentimiento, o qué jurisdicción es la competente, etc., son esenciales en la nueva situación.

En España, diez años más tarde de la aparición del juego por internet, por Orden del Ministerio de Hacienda de 20 de julio de 2005 (BOE de 6 de agosto) se autorizó a LAE (Loterías y Apuestas del Estado) a comercializar sus juegos ${ }^{16}$ por este canal, lo que tiene como novedad que no se requiere la utilización de elementos estancados como son los billetes de lotería sino que se valida la compra (por lo tanto el contrato) y se obtiene la justificación de haberlo hecho todo electrónicamente. de 2011).

14 Resolución 2008/2215 (INI) disponible en <http://www.europal.europa.eu> (consulta 27 de abril

15 El mercado español del juego ocupa el quinto lugar en importancia entre los países europeos y se estima en más de 3 millones los jugadores on line en España (Andrés Alvez, 2010:21)

16 Que son a día de hoy, Lotería Nacional, Lotería Primitiva, Bonoloto, Gordo de la Primitiva, Euromillones, Quiniela de futbol, Quinigol y Apuestas en Hipódromos de carácter supraautonómico. 
La implantación generalizada del juego por internet ha tenido además una consecuencia muy llamativa: la utilización de la extensa y en muchos casos abrasiva publicidad de los juegos por Internet cuando ésta está prohibida para los juegos presenciales. Nos encontramos, pues, ante una cierta desregularización consentida (Andrés Alvez, 2010: 219, 246).

La publicidad en los campos de fútbol, por ejemplo, además del patrocinio de los equipos, reflejado en la camiseta de los jugadores, ha sido tolerada en España aunque no en el extranjero, razón por la que nuestros equipos de fútbol "cambian de chaqueta" y aparecen con otro uniforme en los partidos internacionales. Esta tolerancia -parte de una política pública de Pan y Circo- ha causado notables perjuicios por competencia desleal no sólo a las empresas españolas que explotan juegos presenciales, sino a otras muchas tecnológicas que no se han atrevido a utilizar Internet y otros medios telemáticos sin previa autorización, como exige la vigente legislación (televisiones, compañías telefónicas, etc.).

El testimonio en octubre de 2006 del entonces director de la Asesoría Jurídica de Sogecable, Juan Carlos Alfonso (2009: 93), es demoledor: "Solo una conclusión desde la perspectiva de un operador (Sogecable) que cumple y le gusta cumplir la ley: parece que esta situación de dilación de la regulación administrativa, de que nos encontremos con estas situaciones paradójicas, de que tengamos todo lleno de publicidad, todo el campo de fútbol con publicidad de Bet\&Win, y nosotros no podamos ponerla, que se estén organizando juegos a través de medios telemáticos por vía de la combinación aleatoria, que se pueda hacer en una página web y no haya sanción. Creemos que por unas reglas sanas de competencia, tanto entre el juego privado como público, como entre las empresas de juego situadas en España que pueden pagar sus impuestos estrictamente, el que haya actores inevitables, necesita una regulación y la amenaza no creo que sea buena como acción administrativa, y el tener la espada de Damocles en temas jurídicos-administrativos de una calificación como delito de contrabando, o una posibilidad de cierre de una emisora, o de un medio de comunicación, no es una situación deseable, no fomenta la seguridad jurídica y creo que no es bueno tampoco para el ciudadano".

De la Cruz Ayuso (2010: 93) subraya que "el juego, en general, es un mercado en el que confluyen muchos y muy poderosos intereses económicos, en el que se pone en juego bienes sociales sustantivos y en el que operan organizaciones con más poder e influencia incluso que algunos gobiernos encargados de regular normativamente esta actividad". Con la publicidad ilegal (por no autorizada) asombrosamente consentida durante mucho tiempo tanto por los ejecutivos autonómicos como por el gobierno central se ha puesto en claro que el interés a proteger por las políticas públicas, caso que éstas hubiesen sido coherentes, no es, ahora, ni la protección de la infancia (¿cuántos miles de niños llevan puestas las camisetas de sus ídolos que publicitan las apuestas on-line?), ni la transparencia y seguridad del juego (¿dónde están radicados los servidores y quien los controla?) ni los intereses fiscales del Estado y de las comunidades autónomas, ya que estas compañías actúan en Es- 
paña sin autorización desde paraísos fiscales y no pagan los impuestos que se exigen al juego presencial ${ }^{17}$. Además, la actividad dirigida a fomentar en España la participación en juegos y apuestas organizados por una entidad establecida en otro Estado y desarrollados fuera de España debe ser considerada también una actividad ilícita de contrabando, de acuerdo con la disposición final décimo cuarta de la Ley 42/2006, de 28 de diciembre, de Presupuestos Generales del Estado para el año 2007 que modifica la Ley 46/1985 de 27 de diciembre, de Presupuestos Generales del Estado para 1986.

Este criterio acaba de corroborarlo el profesor Castro Moreno (2010: 15-21): “Por consiguiente se puede concluir con base al citado principio de territorialidad, interpretado a la luz del criterio de ubicuidad, que una vez afirmada la tipicidad penal de la conducta objeto de análisis conforme a la legislación penal española como un delito de contrabando, y dado que se está ofreciendo participar en los juegos ilegales a internautas situados en territorio español, los tribunales españoles y, en concreto, la Audiencia Nacional, al ofrecerse el juego a internautas de más de una provincia (artículo 65.1.c de la LOPJ) resultarían competentes para conocer del presunto delito".

Por otro lado, el artículo 15 de la Ley 3/1991, de 10 de enero, de Competencia Desleal, tipifica como desleal la violación de las normas del ordenamiento jurídico cuando permita a su autor la obtención de una ventaja competitiva significativa, lo que ha permitido presentar una demanda ante los juzgados madrileños de lo mercantil contra Bwin por parte de una empresa de juego presencial española.

Resulta curioso observar cómo estas compañías de apuestas que actúan ilegalmente rehúyen toda responsabilidad haciéndola recaer sobre el jugador, al que se advierte, en el momento de entrar en su página web y de inscribirse como socio, de que "al presentar esta solicitud Vd. certifica que las apuestas por Internet son legales en su país... y Vd. certifica que (aquí la compañía de la que se trate) no es responsable de la precisión de la información que Vd. ha proporcionado".

Con ello arribamos a la última iniciativa que es la Ley de Regulación del Juego que como es patente, queda fuera del objeto de este artículo.

17 Ya en 1994, Muñoz Machado, en su intervención en la $4^{a}$ Mesa Redonda de las /l Jornadas de Legislación sobre el Juego señalaba que en la regulación del sector del juego "se ha producido una de las mayores paradojas de la historia moderna de los Estados de Derecho, consistente en que el ordenamiento jurídico ha dispuesto mejores recursos para sancionar las infracciones de la legislación vigente por parte de quienes operan en su marco legalmente, que para sancionar el juego ilegal: se ha insistido en establecer mecanismos represivos muy eficientes para los operadores de casinos, o de máquinas, o de bingos, pero ninguno o prácticamente ninguno para los que organizan garitos en los que practicar el juego, quienes han tenido, de esta forma, la posibilidad de desarrollar su actividad sin temer mucho a la Administración Pública. La paradoja, que no es sino el resultado de tanto mirar de cerca, de tanto tutelar a los autorizados, ha llegado hasta el extremo de que una Ley de presupuesto -la que se aprobó el 27 de diciembre de 1985, de presupuestos para el año 86- llegó a condenar algunas infracciones de la legislación del juego como contrabando, cuando las infracciones cometidas por los empresarios de juego no autorizados no tenían ningún tipo de represión". 


\section{CONCLUSIONES}

1) La regulación del juego en España adolece de falta de conocimientos técnicos, tanto por parte del legislador como de los reguladores ${ }^{18}$. En algunos casos ha sido una normativa importada, y en la que resulta ser autóctona ha ido gestándose y conformándose de acuerdo con la experiencia adquirida y acumulada. Así se reconoce en varias exposiciones de motivos de diferentes normas que no hacen más que subrayar que la acción legislativa ha ido siempre a remolque de la realidad.

Al cabo de una década de la despenalización del juego, en determinado momento y a causa de la transferencia de las competencias con carácter exclusivo del juego a las Comunidades del artículo 151, apareció la conflictividad como elemento determinante. Ello ha supuesto ante todo un forcejeo jurisdiccional y, a la postre, la paralización de la acción normativa innovadora por parte del Estado, pues el "síndrome de la LOAPA" ha estado presente en todo momento. Esto no significa que, por su parte, las comunidades autónomas no adoptaran medidas sino que a pesar de ser éstas numerosísimas no hicieron frente, en líneas generales, a los problemas sustanciales, por ejemplo la no territorialidad, como se reconoce en la exposición de motivos de la Ley de Regulación del Juego que acaba de promulgarse (Ley 13/2011, de 27 de mayo, BOE de 28 de mayo de 2011).

2) Hasta el momento las políticas públicas se han desarrollado "a trompicones" 19 , forzadas siempre entre la presión proveniente de una sedicente moral social pazguata y superficial y los intereses mercantiles de los gestores de juegos (incluidos los públicos: LAE y ONCE), sin olvidar las necesidades recaudatorias de las administraciones públicas. Finalmente, en los últimos años, la entrada en el escenario de los equipos de fútbol ha servido de caballo de Troya de las grandes multinacionales de apuestas a cuyos intereses ha acabado plegándose el legislador ${ }^{20}$.

18 Sirva como ejemplo los estrepitosos fracasos de las loterías autonómicas catalanas o de los boletos vascos. "Constituyen una evidencia clara de las equivocaciones a que nos estamos refiriendo en el terreno profesional y de resultados económicos” afirma Iglesias Díaz (1995: 126)

19 Como reconoció en 1994 el director general de Juegos y Apuestas de la Generalitat de Cataluña, Xavier Civit, en su participación en la Mesa Redonda $n^{\circ} 4$ de las /I Jornadas de Legislación sobre el Juego. En ella también afirmó: "Uno de los problemas importantes que tiene planteado el Sector: no hay política de Juego, hay unas pocas ideas definidas sobre cuáles son las soluciones políticas a los problemas que tiene el Sector. Así pues, el panorama legal en España, del que hablamos hoy en esta Mesa número cuatro, viene condicionado por la falta de políticas y alternativas en materia de juego a nivel general".

20 Como anécdota demostrativa de la situación paradójica en la que nos encontramos lo constituye la demanda que en un primer momento interpuso el Real Madrid contra las empresas de apuestas por internet solicitando dejasen de utilizar el nombre y fotografía de sus jugadores, según informó el diario El País de 5 de agosto de 2005, pero que acabó al aceptar el patrocinio de estos operadores como la compensación económica demandada. 


\section{REFERENCIAS BIBLIOGRÁFICAS Y DOCUMENTALES}

Alfonso, J.C. (2009), “El Juego por Internet, televisión y telefonía móvil”, en J.I. Cases y G. Gusano, coords., La Industria del Juego. Pamplona: Thomson-Aranzadi.

Andrés Alvez, R. (2010), "Problemática específica del juego on line y su aplicación a las apuestas deportivas”, en A. Palomar, dir., Las Apuestas Deportivas. Madrid: Thomson-Aranzadi.

Arnaldo Alcubilla, E. (2004), “Monopolio de loterías. Compatibilidad con el Derecho Comunitario”, en J.I. Rodríguez Rodríguez y E. Arnaldo, dirs., Régimen Legal del Juego en España. Madrid: Consejo General del Poder Judicial.

Bañón, R. Ramos, J.A. y Tamayo, M. (1997), "Sistemas de relaciones intergubernamentales y legitimidad de la acción pública en el Estado de las Autonomías", en C. Alba y F.J. Vanaclocha, El sistema político local: Un nuevo escenario de gobierno. Madrid: Universidad Carlos III de Madrid.

Caillois, R. (1986), Los juegos y los hombres. La máscara del miedo. México D.F.: Fondo de Cultura Económica.

Cases, J.I. (2009), “La importancia social y política de la industria del juego en España”, en J.I. Cases y G. Gusano, coords., La Industria del Juego. Pamplona: Thomson-Aranzandi.

Castro Moreno, A. (2010), “Contrabando y apuestas deportivas por Internet”, en Revista de Derecho de Deporte y Entretenimiento, 30: 15-21.

Cruz Ayuso, C. (2010), "El azar reparte las cartas, pero nosotros jugamos. Una aproximación ética al juego responsable”, en M. Cuencia y M. Izaguirre, eds., Ocio y juegos de azar. Bilbao: Universidad de Deusto.

Dye, T. R. (1992), Understanding Public Policy. New Jersey: Prentice Hall.

Farre i Morell, A. (1995), “La organización de la Administración del Juego en España: presente y futuro. Las competencias exclusivas. La coordinación entre las administraciones públicas", en II Jornadas de Legislación sobre el Juego. Madrid: Loyra.

Fernández Allés, J.J. (2002), Las relaciones intergubernamentales en el Derecho Constitucional Español. Cádiz: Universidad de Cádiz.

Freddi, G. (1989), Scienzia dell'Administrazione e Politiche Pubbliche. Roma: La Nuova Italia Scientifica.

García Rodríguez, J.C. (2008), El caso Strauss. El escándalo que precipitó el final de la ll República. Astorga: Akrón.

Gomá, R. y Subirats, J. (1998), Políticas públicas en España. Barcelona: Ariel.

González Gómez, A. (2006), “La cooperación multilateral institucionalizada: las Conferencias Sectoriales”, en L. López Nieto, coord., Relaciones Intergubernamentales en la España democrática. Madrid: Dykinson.

Gusano Serrano, G. (2010), "El universo del ocio y el entretenimiento: una aproximación a los juegos de azar”, en M. Cuenca y M. Izaguirre, eds., Ocio y Juegos de Azar. Bilbao: Universidad de Deusto.

Iglesias Díaz, J.A. (1995), “El panorama legal en España. Reglamentos Autonómicos sectoriales", en II Jornadas de Legislación sobre el Juego. Madrid: Loyra.

IPOLGOB (2010), Una aproximación a la percepción sobre el comportamiento y las actitudes sociales respecto al juego y al juego on-line en España, Monografía Política y

98 Gestión 1/2010: Universidad Carlos III de Madrid. 
IPOLGOB (2010), La gestión de los Juegos Públicos. Especial referencia al proceso de reorganización de los juego del Estado Español, Monografía Política y Gestión 2/2010: Universidad Carlos III de Madrid.

Lalanda, C. (2010), “Los juegos on-line: aspectos legales 2008”, en M. Cuenca y M. Izaguirre, eds., Ocio y Juegos de Azar. Bilbao: Universidad de Deusto.

Landrove Díaz, G. (1978), “Los juegos de azar ante el derecho penal español”, Cuadernos de Política Criminal, 6: 83-112.

Lindblom, C. E. (1991), El proceso de elaboración de políticas públicas. Madrid: INAP.

López Maza, S. (2011), El contrato de juego y apuesta en el ámbito civil. Pamplona: Aranzadi.

López Nieto, L. (2006), “La dimensión institucionalizada de las relaciones intergubernamentales en el Estado Autonómico”, en L. López Nieto, coord., Relaciones intergubernamentales en la España democrática. Madrid: Dykinson.

Meny, Y. y Thoenig, J.C. (1992), Las políticas públicas. Barcelona: Ariel.

Ortega Álvarez, L. (2005), La reforma del Estado Autonómico. Madrid: CEC.

Palomar Olmeda, A. (2006), "La ordenación legal del juego en España”, en A. Palomar, coord., Régimen del Juego en España. Pamplona: Thomson-Aranzadi.

Palomar, A. y Andrés, R. (2008), Código del Juego. Pamplona: Thompson-Aranzadi.

Ramón Fernández, T. (1996), "La distribución de competencias en materia de juegos de Azar: Problemática y soluciones", Álea, 3: 3-7.

Ramos Gil, R. (2007 [1996]), “El juego de azar en España. Evolución histórica. Momento presente”, en J.I. Cases, El juego de azar y la sociedad española. Madrid: Codere.

Romero, J.R. (2007 [1996]), “La normativa de los juegos de azar. Derecho interno y referencia normativas de la Unión Europea”, en J.I. Cases, El juego de azar y la Sociedad Española. Madrid: Codere.

Romero, J.R. (1998), “Coordinación de competencias en materia de juego”, Álea, 11: 7-10.

San Salvador del Valle, R. (2010), “Ocio, juegos de azar y apuestas deportivas” en M. Cuenca y M. Izaguirre, eds., Ocio y juegos de azar. Bilbao: Universidad de Deusto.

Soriano Cabrera, J.A. (2009), "Políticas públicas de juego”, en J.I. Cases y G. Gusano, La Industria del Juego. Pamplona: Thomson-Aranzadi.

Subirats, J. (1996), "Análisis de políticas públicas y gestión pública: promesas y riesgos de una vida en común”, en Lecturas de Gestión Pública. Madrid: INAP.

Tamayo Sáez, M. (1997), “El análisis de las políticas públicas”, en R. Bañón y E. Carrillo, comps., La Nueva Administración Pública. Madrid: Alianza.

Vallés, J.M. (2003), Ciencia Política. Una introducción. Barcelona: Ariel. 


\section{ANEXOS}

\section{TABLA 1}

Variación interanual 2005/2009 de las cantidades jugadas en todos los juegos (en millones de euros)

\begin{tabular}{|c|c|c|c|c|c|c|c|c|c|c|}
\hline & 2005 & \begin{tabular}{|c} 
Variación \\
relativa \\
$05 / 04$
\end{tabular} & 2006 & $\begin{array}{c}\text { Variación } \\
\text { relativa } \\
06 / 05\end{array}$ & 2007 & $\begin{array}{c}\text { Variación } \\
\text { relativa } \\
07 / 06\end{array}$ & 2008 & $\begin{array}{c}\text { Variación } \\
\text { relativa } \\
08 / 07\end{array}$ & 2009 & \begin{tabular}{|c} 
Variación \\
relativa \\
$09 / 08$
\end{tabular} \\
\hline $\begin{array}{l}\text { JUEGOS DE } \\
\text { GESTIÓN PRIVADA }\end{array}$ & 385,57 & 6,00 & 382,31 & $-0,85$ & 416,79 & 9,02 & 436,77 & 4,79 & 391,16 & $-10,44$ \\
\hline Casinos & 55,43 & 17,93 & 55,02 & $-0,73$ & 56,43 & 2,56 & 49,55 & $-12,20$ & 42,59 & $-14,05$ \\
\hline Bingos & 86,91 & $-0,83$ & 82,62 & $-4,93$ & 81,01 & $-1,96$ & 73,11 & $-9,74$ & 62,68 & $-14,26$ \\
\hline Máquinas 'B' (2) & 243,24 & 6,17 & 244,67 & 0,59 & 279,35 & 14,18 & 314,11 & 12,44 & 285,89 & $-8,98$ \\
\hline $\begin{array}{l}\text { LOTERÍAS Y } \\
\text { APUESTAS DEL } \\
\text { ESTADO }\end{array}$ & 210,92 & 2,76 & 215,77 & 2,30 & 220,92 & 2,38 & 217,69 & $-1,46$ & 210,60 & $-3,26$ \\
\hline Lotería Nacional & 118,65 & 4,53 & 121,96 & 2,80 &.. & .. & .. & .. &.. &.. \\
\hline Lotería Primitiva & 50,79 & $-5,22$ & 49,25 & $-3,04$ & .. & .. & .. & .. & .. & .. \\
\hline Bono-Loto & 13,65 & 1,41 & 13,42 & $-1,69$ & .. & .. & .. & .. & .. & .. \\
\hline Quiniela & 11,19 & $-7,83$ & 10,74 & $-4,07$ & .. & .. & .. & .. & .. & .. \\
\hline Otros (3) & 16,64 & 32,57 & 20,40 & 22,59 &.. &.. &.. &.. &.. &.. \\
\hline Juegos Pasivos (4) & .. &.. &.. &.. & 126,41 & 3,64 & 122,31 & $-3,24$ & 116,06 & $-5,11$ \\
\hline Juegos Activos (4) & .. &.. &.. &.. & 94,51 & 0,75 & 95,39 & 0,93 & 94,54 & $-0,89$ \\
\hline ONCE (Cupón) & 45,88 & $-10,84$ & 47,91 & 4,42 & 47,91 & $-0,01$ & 45,51 & $-5,00$ & 42,37 & $-6,89$ \\
\hline TOTAL & 642,37 & 3,53 & 645,99 & 0,56 & 685,61 & 6,13 & 699,97 & 2,09 & 644,13 & $-7,98$ \\
\hline
\end{tabular}

Fuente: Memoria del Juego en España. Subdirección General de Estudios y Relaciones Institucionales. Comisión Nacional del Juego. Ministerio del Interior. Años referenciados. 
TABLA 2

Variación interanual 2005/2009 del gasto real en todos los juegos (en millones de euros)

\begin{tabular}{|c|c|c|c|c|c|c|c|c|c|c|}
\hline & 2005 & $\begin{array}{c}\text { Variación } \\
\text { relativa } \\
05 / 04\end{array}$ & 2006 & $\begin{array}{c}\text { Variación } \\
\text { relativa } \\
06 / 05\end{array}$ & 2007 & $\begin{array}{c}\text { Variación } \\
\text { relativa } \\
07 / 06\end{array}$ & 2008 & $\begin{array}{c}\text { Variación } \\
\text { relativa } \\
08 / 07\end{array}$ & 2009 & $\begin{array}{c}\text { Variación } \\
\text { relativa } \\
09 / 08\end{array}$ \\
\hline $\begin{array}{l}\text { JUEGOS DE GESTIÓN } \\
\text { PRIVADA }\end{array}$ & $4.562,72$ & 5,32 & $4.692,96$ & 2,85 & $5.078,13$ & 8,21 & $5.390,99$ & 6,16 & $4.852,67$ & $-9,99$ \\
\hline Casinos & 550,58 & 16,72 & 552,68 & 0,38 & 556,82 & 0,75 & 498,78 & $-10,42$ & 428,71 & $-14,05$ \\
\hline Bingos & $1.329,83$ & $-0,88$ & $1.405,64$ & 5,70 & $1.364,61$ & $-2,92$ & $1.267,57$ & $-7,11$ & $1.082,94$ & $-14,57$ \\
\hline Máquinas 'B' (2) & $2.682,31$ & 6,48 & $2.734,65$ & 1,95 & $3.156,69$ & 15,43 & $3.624,64$ & 14,82 & $3.341,02$ & $-7,82$ \\
\hline $\begin{array}{l}\text { LOTERÍAS Y } \\
\text { APUESTAS DEL } \\
\text { ESTADO }\end{array}$ & $3.401,65$ & 2,23 & $3.520,73$ & 3,50 & $3.636,39$ & 3,29 & $3.674,89$ & 1,06 & $3.616,33$ & $-1,59$ \\
\hline Lotería Nacional & $1.570,04$ & 4,84 & $1.635,76$ & 4,19 & .. & .. & .. & .. & .. & .. \\
\hline Lotería Primitiva & $1.008,23$ & $-4,94$ & 991,04 & $-1,71$ &. &. & .. & .. &.. &. \\
\hline Bono-Loto & 270,97 & 1,71 & 270,18 & $-0,29$ & .. & .. &. & .. &. & .. \\
\hline Quiniela & 222,13 & $-7,56$ & 215,77 & $-2,87$ & .. &. &. & .. &.$\cdot$ & .. \\
\hline $\operatorname{Otros}(3)$ & 330,27 & 25,83 & 407,99 & 23,53 & .. & .. & .. & .. & .. & .. \\
\hline Juegos Pasivos (4) & .. & .. & .. &.$\cdot$ & $1.922,33$ & 17,52 & $1.693,64$ & $-11,90$ & $1.627,64$ & $-3,90$ \\
\hline Juegos Activos (4) &. &. &.. & .. & $1.714,06$ & $-9,07$ & $1.981,25$ & 15,59 & $1.988,69$ & 0,38 \\
\hline ONCE (Cupón) & $1.052,33$ & $-10,57$ & $1.114,20$ & 5,88 & $1.125,96$ & 1,06 & $1.092,30$ & $-2,99$ & $1.030,02$ & $-5,70$ \\
\hline TOTAL & $9.016,70$ & 2,04 & $9.327,89$ & 3,45 & $9.840,48$ & 5,50 & $10.158,18$ & 3,23 & $9.499,01$ & $-6,49$ \\
\hline
\end{tabular}

Fuente: Memoria del Juego en España. Subdirección General de Estudios y Relaciones Institucionales. Comisión Nacional del Juego. Ministerio del Interior. Años referenciados. 
TABLA 3

Cantidades jugadas por habitante (en millones de euros)

\begin{tabular}{|l|c|c|c|c|}
\hline & 1997 & 2000 & 2005 & 2009 \\
\hline JUEGOS DE GESTIÓN PRIVADA & 308,38 & 393,41 & 385,57 & 391,16 \\
\hline Casinos & 27,73 & 39,32 & 55,43 & 42,59 \\
\hline Bingos & 92,14 & 94,99 & 86,91 & 62,68 \\
\hline Máquinas ‘B' (2) & 188,51 & 259,09 & 243,24 & 285,89 \\
\hline LOTERÍAS Y APUESTAS DEL ESTADO & 150,94 & 171,17 & 210,92 & 210,60 \\
\hline Lotería Nacional & 88,60 & 102,05 & 118,65 &.. \\
\hline Lotería Primitiva & 41,62 & 45,73 & 50,79 &.. \\
\hline Bono-Loto & 8,19 & 11,13 & 13,65 &.. \\
\hline Quiniela & 12,53 & 12,26 & 11,19 &.. \\
\hline Otros (3) &.. &.. & 16,64 &.. \\
\hline Juegos Pasivos (4) &.. &.. &.. & 116,06 \\
\hline Juegos Activos (4) &.. &.. &.. & 94,54 \\
\hline ONCE (Cupón) & 56,46 & 60,50 & 45,88 & 42,37 \\
\hline TOTAL & 515,77 & 625,08 & 642,37 & 644,13 \\
\hline
\end{tabular}

Fuente: Memoria del Juego en España. Subdirección General de Estudios y Relaciones Institucionales. Comisión Nacional del Juego. Ministerio del Interior. Años referenciados.

\section{Notas referidas a las tablas 1, 2 y 3 de los anexos}

1) El gasto real es la cantidad jugada menos los premios obtenidos.

2) Las Máquinas 'B' son las que, a cambio del precio de la partida, conceden al usuario un tiempo de juego y, eventualmente, de acuerdo con el programa de juego, un premio en metálico, según artículo 5 del Real Decreto 2110/1998, de 2 de octubre.

3) Hasta 2005, en el apartado Otros, únicamente se incluía el juego del Euromillón. A partir de 2005, además del Euromillón se incluyen nuevos juegos como: Lototurf, Quintuple Plus y Quinigol. A partir de 2006, también se incluye la cantidad jugada en el Canal Internet LAE.

4) A partir de 2007 , el total de 'Loterías y Apuestas del Estado’ engloba los Juegos Pasivos (Lotería Nacional del jueves y sábado) y el resto de juegos o Juegos Activos (Quiniela, Quinigol, Conjunto de la Primitiva-Lotería Primitiva, Gordo de la Primitiva, Bono-Loto, Euromillones-Lototurf y Quíntuple Plus), se agrupan para hacer compatible su comparación con la distribución de años anteriores. 
TABLA 4

Distribución del gasto real y de las cantidades jugadas entre los diferentes juegos.

Año 2009

\begin{tabular}{|l|c|c|}
\hline & GASTO REAL & CANTIDADES JUGADAS \\
\hline JUEGOS DE GESTIÓN PRIVADA & $51,1 \%$ & $60,7 \%$ \\
\hline Casinos & $4,5 \%$ & $6,6 \%$ \\
\hline Bingos & $11,4 \%$ & $9,7 \%$ \\
\hline Máquinas ‘B’ & $35,2 \%$ & $44,4 \%$ \\
\hline LOTERÍAS Y APUESTAS DEL ESTADO & $38,1 \%$ & $32,7 \%$ \\
\hline Juegos Pasivos & $17,1 \%$ & $18,0 \%$ \\
\hline Juegos Activos & $20,9 \%$ & $14,7 \%$ \\
\hline ONCE (Cupón) & $10,8 \%$ & $6,6 \%$ \\
\hline TOTAL & $100,0 \%$ & $100,0 \%$ \\
\hline
\end{tabular}

Fuente: Memoria del Juego en España. Subdirección General de Estudios y Relaciones Institucionales. Comisión Nacional del Juego. Ministerio del Interior (2009).

Recibido: 10 de marzo de 2011

Aceptado: 30 de mayo de 2011 
